
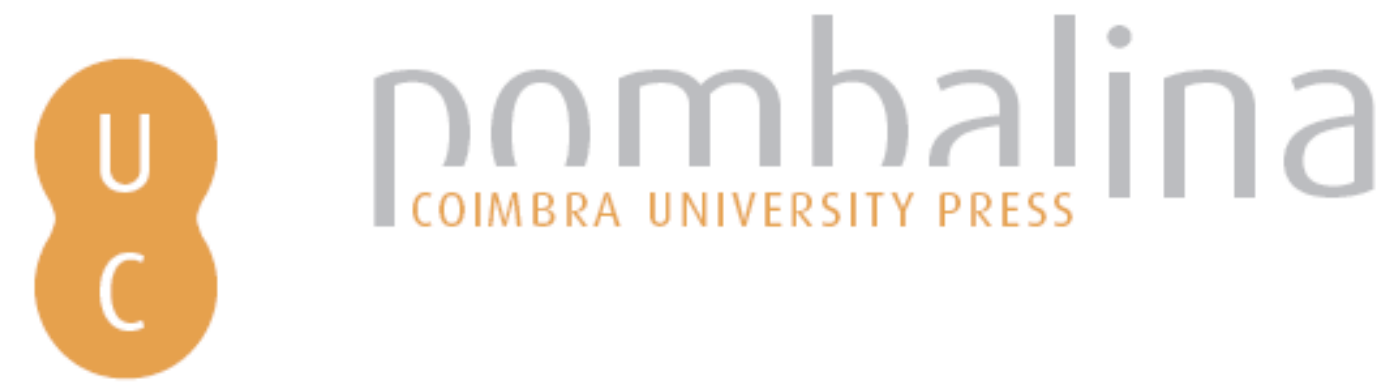

\title{
Caracterização e usos terapêuticos de produtos de origem marinha nos Comentários de Amato Lusitano a Dioscórides
}

\author{
Autor(es): $\quad$ Fernandes, José Sílvio Moreira \\ Publicado por: UA Editora - Universidade de Aveiro; Imprensa da Universidade de \\ URL \\ persistente: \\ Coimbra; Annablume \\ DOI: \\ URI:http://hdl.handle.net/10316.2/35704 \\ DOI:http://dx.doi.org/10.14195/978-989-26-0941-6_18 \\ Accessed : $\quad$ 26-Apr-2023 11:18:27
}

A navegação consulta e descarregamento dos títulos inseridos nas Bibliotecas Digitais UC Digitalis, UC Pombalina e UC Impactum, pressupõem a aceitação plena e sem reservas dos Termos e Condições de Uso destas Bibliotecas Digitais, disponíveis em https://digitalis.uc.pt/pt-pt/termos.

Conforme exposto nos referidos Termos e Condições de Uso, o descarregamento de títulos de acesso restrito requer uma licença válida de autorização devendo o utilizador aceder ao(s) documento(s) a partir de um endereço de IP da instituição detentora da supramencionada licença.

Ao utilizador é apenas permitido o descarregamento para uso pessoal, pelo que o emprego do(s) título(s) descarregado(s) para outro fim, designadamente comercial, carece de autorização do respetivo autor ou editor da obra.

Na medida em que todas as obras da UC Digitalis se encontram protegidas pelo Código do Direito de Autor e Direitos Conexos e demais legislação aplicável, toda a cópia, parcial ou total, deste documento, nos casos em que é legalmente admitida, deverá conter ou fazer-se acompanhar por este aviso.

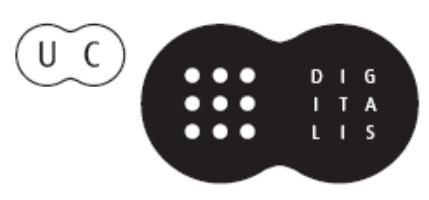




\section{HUMANISMO E CIÊNCIA Antiguidade e Renascimento}

António Manuel Lopes Andrade

Carlos de Miguel Mora

João Manuel Nunes Torrão
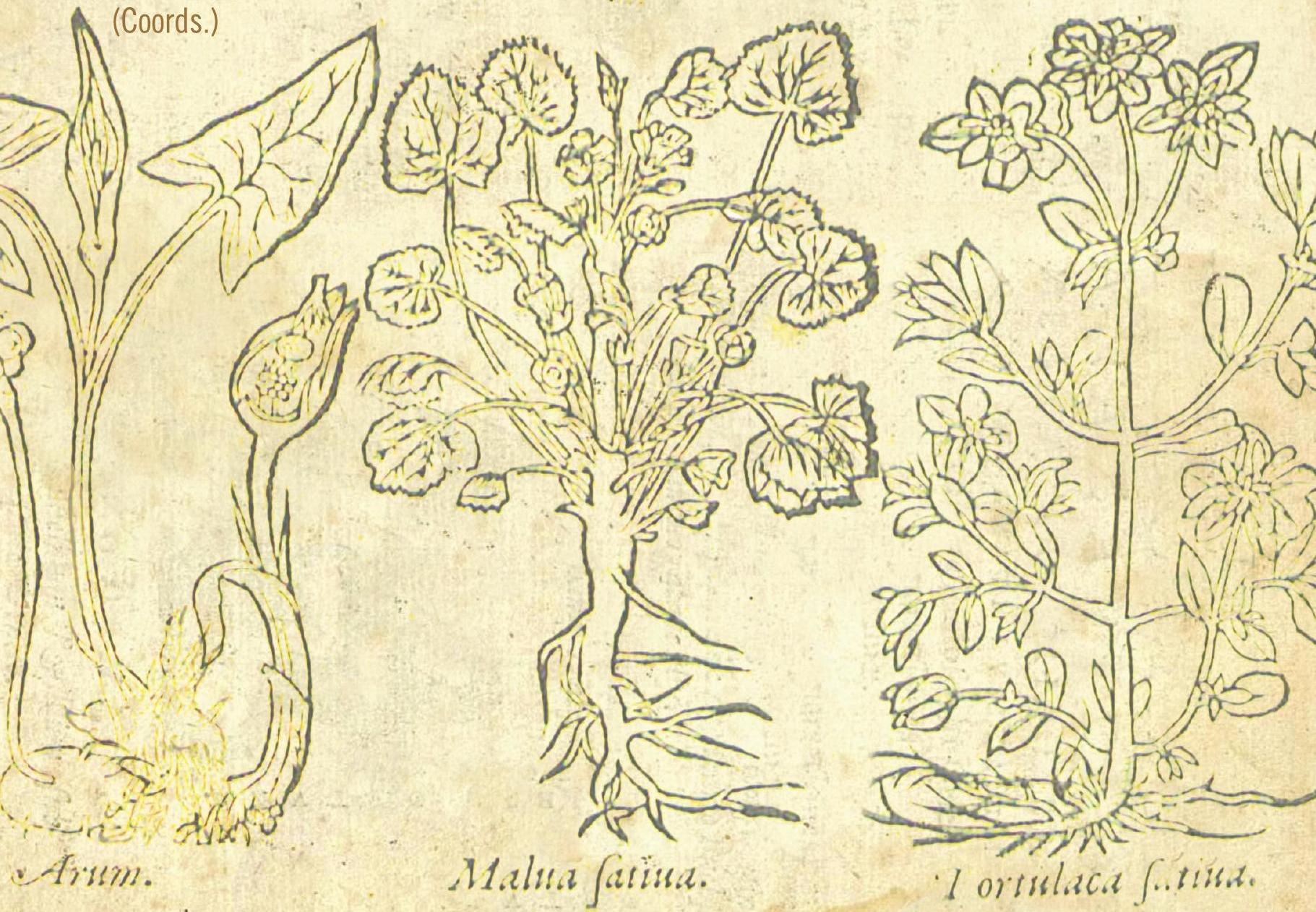

Aveiro I Coimbra I São Paulo 2015

UA Editora - Universidade de Aveiro I Imprensa da Universidade de Coimbra I Annablume 
Este volume resulta de várias iniciativas desenvolvidas no âmbito do projecto de I\&D "Dioscórides e o Humanismo Português: os Comentários de Amato Lusitano" (http://amatolusitano.web.ua.pt), recoIhendo contribuições de mais de duas dezenas de colaboradores, tanto de membros da equipa como de outros investigadores nacionais e estrangeiros. Entre os eventos que estiveram na origem deste livro destacam-se as três edições do Ciclo de Conferências promovido pelo projecto, realizadas entre 2010 e 2013, e sobretudo o Colóquio Internacional "Dioscórides e o Humanismo Português: os Comentários de Amato Lusitano", que decorreu no Departamento de Línguas e Culturas da Universidade de Aveiro, nos dias 21 e 22 de Novembro de 2013.

0 objectivo principal do projecto é a edição e tradução para português dos dois livros que Amato Lusitano dedicou ao comentário do tratado grego De materia medica de Dioscórides, ou seja, o Index Dioscoridis (Antuérpia, 1536) e as In Dioscoridlis Anazarbei de medica materia libros quinque... enarrationes (Veneza, 1553), estando contemplada, também, a tradução de mais duas obras directamente correlacionadas com os livros do médico português: a montante, a do próprio tratado grego de Dioscórides; a jusante, a do livro intitulado Apologia adversus Amathum Lusitanum (Veneza, 1558) de Pietro Andrea Mattioli.

OBRA PUBLICADA COM A COORDENAÇÃO

CIENTÍFICA DE:

Centro de Línguas, Literaturas e Culturas da Universidade de Aveiro

Centro de Estudos Clássicos e Humanísticos da Universidade de Coimbra

Cátedra de Estudos Sefarditas "Alberto

Benveniste" da Faculdade de Letras da Universidade de Lisboa 


\section{HUMANISMO E CIÊNCIA}

\section{Antiguidade e Renascimento}

ANTÓNIO MANUEL LOPES ANDRADE

CARLOS DE MIGUEL MORA

JOÃO MANUEL NUNES TORRÃO

(COORDS.)

AVEIRO • COIMBRA • SÃO PAULO

2015

UA EDITORA • UNIVERSIDADE DE AVEIRO

IMPRENSA DA UNIVERSIDADE DE COIMBRA

ANNABLUME 


\section{HUMANISMO E CIÊNCIA: Antiguidade e Renascimento}

\author{
EDIÇÃO

UA EDITORA • UNIVERSIDADE DE AVEIRO
IMPRENSA DA UNIVERSIDADE DE COIMBRA
ANNABLUME

ORGANIZAÇÃO E COORDENAÇÃO EDITORIAL ANTÓNIO MANUEL LOPES ANDRADE

CARLOS DE MIGUEL MORA

JOÃO MANUEL NUNES TORRÃO

\author{
DESIGN DA CAPA \\ MEIOKILO DESIGN STUDIO
}

DESIGN

CARLOS COSTA

IMPRESSÃO E ACABAMENTO

SERSILITO • MAIA

ISBN

UA • 978-972-789-434-5

IUC • 978-989-26-0940-9

\section{ISBN DIGITAL}

UA • 978-972-789-435-2

IUC • 978-989-26-0941-6

DOI

http://dx.doi.org/10.14195/ 978-989-26-0941-6

DEPÓSITO LEGAL 368241/13

TIRAGEM 500 Exemplares

(C) 2015

UA EDITORA • UNIVERSIDADE DE AVEIRO IMPRENSA DA UNIVERSIDADE DE COIMBRA

ANNABLUME

\section{COMISSÃO CIENTÍFICA}

António Manuel Lopes Andrade

Carlos de Miguel Mora

Delfim Ferreira Leão

Henrique Leitão

João Manuel Nunes Torrão

Maria de Fátima Reis

Maria do Céu Zambujo Fialho

Miguel Ángel González Manjarrés

\section{TEXTOS}

Adelino Cardoso

Ana Leonor Pereira

Ana Margarida Borges

António Guimarães Pinto

António Maria Martins Melo

Bernardo Mota

Carlos A. Martins de Jesus

Carlos de Miguel Mora

Cristina Santos Pinheiro

Donald Beecher

Emília Oliveira

Isabel Malaquias

James W. Nelson Novoa

Joana Mestre Costa

João Manuel Nunes Torrão

João Rui Pita

Jorge Paiva

José Sílvio Moreira Fernandes

Maria de Fátima Silva

Miguel Ángel González Manjarrés

Rui Manuel Loureiro

Telmo Corujo dos Reis

Teresa Nobre de Carvalho

Vinicije B. Lupis

Virgínia Soares Pereira 


\section{HUMANISMO E CIÊNCIA}

\section{Antiguidade e Renascimento}

ANTÓNIO MANUEL LOPES ANDRADE

CARLOS DE MIGUEL MORA

JOÃO MANUEL NUNES TORRÃO

(COORDS.)

AVEIRO • COIMBRA • SÃO PAULO

2015

UA EDITORA • UNIVERSIDADE DE AVEIRO

IMPRENSA DA UNIVERSIDADE DE COIMBRA

ANNABLUME 
OBRA PUBLICADA

COM A COORDENAÇÃO

CIENTÍFICA DE:

CENTRO DE LÍNGUAS,

LITERATURAS E CULTURAS DA

UNIVERSIDADE DE AVEIRO

CENTRO DE ESTUDOS

CLÁSSICOS E HUMANÍSTICOS DA

UNIVERSIDADE DE COIMBRA

CÁTEDRA DE ESTUDOS SEFARDITAS

"ALBERTO BENVENISTE"

DA FACULDADE DE LETRAS DA

UNIVERSIDADE DE LISBOA 


\section{SUMÁRIO}

PREFÁCIO

1.1 "Teofrasto, Tratado das plantas. No alvor de uma nova ciência" 13

Maria de Fátima Silva

1.2 "Francisco de Melo e os fragmentos de teoria óptica de Pierre Brissot" 21 Bernardo Mota

1.3 "Algumas reflexões sobre as pedras preciosas nos Colóquios dos simples de Garcia de Orta" 37 Rui Manuel Loureiro

1.4 "Estratégias, patronos e favores em Colóquios dos Simples de Garcia de Orta" 63 Teresa Nobre de Carvalho

1.5 "As plantas na obra poética de Camões (épica e lírica)" 95 Jorge Paiva

1.6 "Nicolás Monardes, John Frampton and the Medical Wonders of the New World" .141 Donald Beecher

1.7 "Literatura e Medicina: alguns textos de Justo Lípsio e de dois doutores Luís Nunes" 161 António Guimarães Pinto

1.8 "Ontologias e idiossincrasias dos Amantes, à luz da Archipathologia de Filipe Montalto" ...... 211 Joana Mestre Costa \& Adelino Cardoso

1.9 "Gabriel da Fonseca. A New Christian doctor in Bernini's Rome". .227 James W. Nelson Novoa 


\section{2) DIOSCÓRIDES E O HUMANISMO PORTUGUÊS: OS COMENTÁRIOS DE AMATO LUSITANO}

2.1 "Léxico científico português nos Comentários de Amato: antecedentes e receção"

Ana Margarida Borges

2.2 "Usos medicinais das plantas, em Amato Lusitano: o bálsamo"

António Maria Martins Melo

2.3 "Amato Lusitano e a importância da ilustração botânica no século xVI.

Em torno das edições lionesas das Enarrationes (1558)"

Carlos A. Martins de Jesus

2.4 "Sobre la identificación entre ébano y guayaco en una entrada

del Index Dioscoridis de Amato Lusitano".

Carlos de Miguel Mora

2.5 "Os partos distócicos em Amato Lusitano e em Rodrigo de Castro:

fontes, doutrinas e terapias greco-romanas"

\section{Cristina Santos Pinheiro}

2.6 "Do carvalho ao castanheiro: usos e propriedades medicinais

de fagáceas nas Enarrationes de Amato Lusitano".

Emília Oliveira

2.7 "O mundo mineral nos Comentários a Dioscórides de Amato Lusitano".

Isabel Malaquias \& Virgínia Soares Pereira

2.8 "Alguns comentários de Amato: entre a estranheza e a realidade"

João Manuel Nunes Torrão

2.9 "Caracterização e usos terapêuticos de produtos de origem marinha

nos Comentários de Amato Lusitano a Dioscórides"

José Sílvio Moreira Fernandes

2.10 "La mandrágora de Amato Lusitano: edición, traducción y anotación"

Miguel Ángel González Manjarrés

2.11 "O vinho e os vinhos - usos e virtudes de um dom dos deuses

nas Enarrationes de Amato Lusitano"

Telmo Corujo dos Reis

2.12 "Amatus Lusitanus e Didaco Pirro: due ebrei portoghesi

e cerchia umanistica di Dubrovnik" 481

Vinicije B. Lupis

2.13 "Estudos contemporâneos sobre Amato Lusitano". 513

João Rui Pita \& Ana Leonor Pereira 


\title{
Caracterização e usos terapêuticos de produtos de origem marinha nos Comentários de Amato Lusitano a Dioscórides ${ }^{1}$
}

\author{
JOSÉ SÍLVIO MOREIRA FERNANDES²
}

\section{RESUMO:}

No início do segundo livro dos comentários a Dioscórides, Amato Lusitano trata das características e usos terapêuticos de alguns produtos de origem marinha, derivados do ouriço-do-mar, do cavalo-marinho, de búzios, púrpuras e de outras conchas. Assinala sobretudo as propriedades expurgativas, digestivas, evacuativas, cáusticas, estimulantes do leite materno e do ventre, as aplicações em afeções dos rins, dos olhos e do coração, bem como os usos em cosmética feminina.

\section{PALAVRAS-CHAVE:}

Amato Lusitano; Dioscórides; ouriço-do-mar; cavalo-marinho; púrpura.

\section{ABSTRACT:}

In the beginning of the second book of comments to Dioscorides, Amato Lusitano analyzes the characteristics and the therapeutic uses of some marine origin products as sea urchin, sea horse, purple and other shells. Amato specifies in particular the expurgative, digestive, purgative and caustic properties of these products as well as properties for stimulating breastmilk and the belly, the applications for kidneys, eyes and heart diseases, and for uses in women's cosmetics.

\section{KEYWORDS:}

Amatus Lusitanus; Dioscorides; sea urchin; sea horse; purple.

1 Este trabalho foi desenvolvido no âmbito do projeto de I\&D "Dioscórides e o Humanismo Português: os Comentários de Amato Lusitano" (http://amatolusitano.web.ua.pt) do Centro de Línguas, Literaturas e Culturas da Universidade de Aveiro, financiado por Fundos FEDER através do Programa Operacional Factores de Competitividade - COMPETE e por Fundos Nacionais através da FCT - Fundação para a Ciência e a Tecnologia, no âmbito do projeto FCOMP-01-0124-FEDER-009102.

2 Universidade da Madeira; Centro de Línguas, Literaturas e Culturas da Universidade de Aveiro. silvio@uma.pt. 
No início do Livro II das Enarrationes (1553) Amato Lusitano discorre sobre os temas relacionados com alguns animais de origem marinha que mereceram a atenção de Dioscórides na composição do seu De medica materia. No conjunto desta obra de Dioscórides, é assinalável a desproporção existente entre o tratamento dado a temas e assuntos reservados às plantas, em comparação com a diminuta preferência pelo estudo dos animais.

Interessa-nos no presente estudo acompanhar a sequência expositiva e a metodologia escolhida pelo autor, para examinar aspetos relevantes como a descrição tipológica, os usos e aplicaçôes medicinais, e a não menos valiosa informação atinente ao espetro que vai desde as simples atribuições terminológicas às tão importantes prescriçôes terapêuticas. Aqui e ali, Amato recorre à sua vasta erudição para acrescentar informação específica ou complementar, inscrita na tratadística relativa à matéria em causa, assim como de outra tradição textual ou ainda dos usos e costumes registados na memória coletiva.

Iniciando a análise dos animais marinhos, Amato Lusitano trata do tema do ouriço-do-mar, com a particularidade de remeter, desde início, para o seu equivalente terrestre e para as fontes que consultou: Aristóteles, Plínio, Galeno, Teodoro Gaza de Tessalonica ${ }^{4}$ e Paulo Jóvio. ${ }^{5}$ Usa igualmente informação produzida por estes autores para conferir a exatidão da designação de ouriço-do-mar e de ouriço terrestre, como a de Teodoro Gaza, que, na sua tradução de Aristóteles, talvez influenciado por Plínio, reduz aquelas distintas denominaçôes apenas à designação tipológica de ouriço. Segue-se a caracterização anatómica do ouriço-do-mar. Salienta, a este propósito, alguns factos como a semelhança deste ouriço com o ouriço do castanheiro, a tradição associada ao meio natural onde o ouriço-do-mar se desenvolve (particularmente nos mares Adriático e Tirreno) e, finalmente, a aplicação deste produto como estimulante da urina. A sua indicação terapêutica para afeçōes do trato urinário é decerto uma das que mais se encontra registada na tratadística médica. Amato refere-se, ainda neste contexto, ao facto de

3 In Dioscoridis Anazarbei de medica materia libros quinque enarrationes eruditissimae doctoris Amati Lusitani Medici ac Philosophi Celeberrimi... Venetiis, MDLIII.

4 Teodoro Gaza de Tessalonica (c. 1400-1475) foi um eminente autor do Renascimento, conhecido sobretudo pelas suas traduções para latim de obras de autores como Aristóteles (Problemata, De partibus animalium, de generatione animalium), Teofrastro (Historia plantarum) ou Dionísio de Halicarnasso (De compositione verborum). Também traduziu para grego obras de Cícero, como o De Senectute e o Somnium Scipionis. De sua própria autoria, contam-se a obra De origine Turcarum e uma gramática grega, escrita em grego, que Erasmo traduziu para latim. Sobre o autor, ver Pieter BulLens; Allan GotTHELF, "Theodore Gaza's Translation of Aristotle's De Animalibus: Content, Influence, and Date", Greek, Roman, and Byzantine Studies 47 (2007), pp. 469-513; e Deno John Geanakoplos, "Theodore Gaza, a Byzantine Scholar of the Palaeologan 'Renaissance' in the Early Italian Renaissance (c. 14001475)", Constantinople and the West, Essays on the Late Byzantine (Palaeologan) and Italian Renaissances and the Byzantine and Roman Churches. Madison WI, 1989, pp. 68-90.

5 Paulo Jóvio (1483-1552), médico, historiador, biógrafo e cronista, embora seja mais conhecido por ter elaborado uma monumental história do seu tempo (Historiarum sui temporis libri XLV), por ter escrito biografias de homens ilustres e crónicas de temática bélica, tornou-se uma fonte importante para a história da ciência com o seu pequeno tratado De romanis piscibus (1524). 
Aristóteles, na sua História dos Animais, ${ }^{6}$ não fazer menção à eficácia do grande ouriço-do-mar contra defluxos urinários, mas apenas ao tipo mais pequeno de ouriço.

O tratamento da matéria relativa ao ouriço-do-mar fica completo com a referência a Galeno, com remissão para o tratado Sobre as Propriedades dos Medicamentos Simples, de onde retira a citação sobre as virtudes do ouriço: "o corpo queimado de ambos os ouriços, o do mar e o da terra, feito inteiramente em cinzas, possui propriedades expurgativas, digestivas e evacuativas". Acresce que a substância é igualmente eficaz em excrescências e chagas.

A alusão inicialmente feita ao ouriço terrestre fez Amato abreviar a exposição que a ele estava reservada. Ainda assim, completa a caracterização deste ouriço com o que o torna semelhante ao ouriço-do-mar, ao teixo ou ao histrix, ${ }^{7}$ concluindo que se trata de um animal de natureza fria, mas repleto de propriedades e, por isso, muito adequado para a alimentação e para a medicina. Nesse sentido, às propriedades, atrás mencionadas, adjunta a que Dioscórides considerou indicada para o tratamento da queda de cabelo.

Merece, neste passo, que se isole o comentário de Amato a Rasis ${ }^{8}$ que também se refere, na obra Sobre os Sessenta Animais, ao ouriço terrestre. O nosso lusitano manifesta-se convicto do carácter apócrifo de muito do que se atribui ao médico persa sobre este assunto. Tal procedimento ilustra bem a atitude crítica de Amato relativamente às fontes, não se escusando, por isso, de as recusar, mesmo que consideradas como autênticas.

Segue-se o tema do cavalo-marinho ou hipocampo, que atualmente concita a atenção da comunidade científica não só por designar a área do cérebro humano que está associada à memória e à imaginação, ${ }^{9}$ mas também pelo facto de se ter conseguido, no Algarve, reproduzir este animal em cativeiro, com prevista aplicação comercial no ramo da aquariofilia. ${ }^{10}$

Retomando a lógica expositiva, Amato Lusitano começa pelos mares de Ancona, para indicar um dos ambientes naturais onde observou o cavalo-marinho e onde verificou que os pescadores designavam este animal com os termos "dragão" ou "cavalinho curvado". Salienta, a propósito da caracterização anatómica do cavalo-marinho, a coloração quase negra, a forma

6 Cf. Maria de Fátima de Sousa e SILva, Aristóteles, História dos animais, vol. I, 2006; vol. II. Lisboa, INCM, 2008.

7 Género de mamíferos roedores.

8 Antropónimo latino do ilustrado médico, filósofo e alquimista persa atribuído a Muhammad ibn Zakarīya al-Rāzi, que viveu entre os sécs. Ix e x d. C.

9 Foi atribuído o nome de hipocampo à referida área do cérebro humano, por causa da sua semelhança com a forma do cavalo-marinho (hippocampus).

10 Os biólogos Jorge Palma e Miguel Correia, investigadores do Centro de Ciências do Mar da Universidade do Algarve, conseguiram obter resultados positivos na reprodução em cativeiro do cavalo-marinho de focinho comprido (hippocampus guttulatus). Sobre este tipo de investigação, cf. Miguel CorREIA; Jorge PALMA; Heather Koldewey; José P. ANDRADE, "Can artificial holdfast units work as a habitat restoration tool for long-snouted seahorse (Hippocampus guttulatus Cuvier)?", Journal of Experimental Marine Biology and Ecology 448, 1 (2013), pp. 258-264. 
equina, alongada e redonda da cabeça, o pescoço largo, e a cauda fina e curvada. No entanto, a parte mais importante da exposição acaba por ficar reservada às questôes etimológicas, certamente motivadas pela animadversão ao humanista Mattioli de Siena, ${ }^{11}$ numa discussão sobre o significado de "hippo" em plantas como hipposelinus" [salsa-de-cavalos] e em hippomarathrus [funcho bravo] ou em animais como o hipocampo e o hipopótamo. Os argumentos que Mattioli apresenta, na sua Apologia contra as críticas de Amato, podem resumir-se à questão fundamental de que o médico lusitano não prova, de forma inequívoca, que o hipocampo dos Gregos corresponde inteiramente ao cavalo-marinho dos Latinos. Para tal aduz um conjunto de fontes, entre as quais sobressai a de Plínio, para mostrar que existem possibilidades de identificação do hipocampo com animais de dimensão semelhante à dos golfinhos e, seguindo doutíssimos tradutores de Dioscórides, também com a lagosta. ${ }^{12}$

De resto, no que de mais significativo se pode retirar quanto à aplicação do cavalo-marinho na prática médica, Amato recorre à tradição popular italiana para especificar que as mulheres de Ancona usavam este "peixinho", reduzido a pó e tomado com vinho, como potente estimulante do leite materno, como Dioscórides reporta e como o próprio Amato tinha comprovado numa experiência.

O comentário seguinte, assaz mais longo e descritivo do que os anteriores, trata da púrpura e dos búzios. A extensão da exposição muito deve à preocupação do médico albicastrense em discriminar características e em enriquecer o tema com recurso a fontes mitológicas (Hércules e Tritão) e históricas (Júlio César e Tibério César), e à tratadística, recorrendo a autores como Aristóteles, Vitrúvio, Dioscórides, Plínio-o-Velho, Galeno e Francisco Massário. ${ }^{13}$

A este propósito, torna-se aqui importante observar os passos que o autor dá no sentido de prover a exposição da maior quantidade possível de informação, como se pode comprovar pela sequência que nos apresenta sobre a púrpura e os búzios: são "conchas" marinhas; a púrpura é mais valiosa do que o búzio; o líquido que lhe é extraído, enquanto viva, adquiriu fama por servir para tingir de vermelho as vestes de imperadores e de reis; o cão de Hércules está associado à descoberta da púrpura; os Latinos atribuem-lhe diferentes denominações; as púrpuras têm a capacidade de se manterem vivas fora de água durante quase dois meses; de acordo com Aristóteles, Plínio e Massário, permanecem escondidas, durante um mês, no início do ciclo

11 Pier Andrea Mattıolı (Siena, 1501- Trento, 1577), médico e botânico italiano, especialmente conhecido pela sua edição latina da obra de Dioscórides (Commentarii in libros sex Pedacii Dioscoridis Anazarbei, de medica materia. Venetiis, apud Vincentium Valgrisium, 1554) e pela atitude censória contra Amato Lusitano, a respeito das suas Enarrationes, de que é exemplo a publicação da Apologia adversus Amathum Lusitanum, cum censura in eiusdem enarrationes. Venetiis, Vincentii Valgrisii \& Balthassar Costantini, 1558. O "hippocampus" é um das vinte defesas de Mattioli às críticas de Amato.

12 Cf. P. A. Mattioli, Apologia adversus..., op. cit., ed. 1559, p. 13.

13 Comentador de Plínio-o-Velho, na obra In nonum Plinii de naturali historia librum... Basileae, Froben, 1537. 
ditado pela constelação do Cão; existe uma semelhança entre a palavra "búzio" e o som que produz; ao som de um búzio Tritão ${ }^{14}$ terá cantado aos habitantes de Lisboa; os búzios, por conselho de Dioscórides e de Galeno, são eficazes para limpar chagas; os Portugueses fazem uso quotidiano dos caros búzios cor de pérola, importados da Índia; existem conchas que produzem pérolas, as margaritas ou pérolas vulgares e a pérola única, isto é, a das conchas que produzem uma única pérola; o uso médico das pérolas é importantíssimo, como a tradição árabe reporta, para o tratamento de afeçóes oculares e cardíacas; as pérolas importadas da Índia são de cor amarelada, por causa da ação do Sol; as que vêm do Peru são muito brancas e de elevado valor; as mais perfeitas são as produzidas no Mar Vermelho, que os Portugueses comercializam e importam; as pérolas usadas adquirem cor amarelada e ficam rugosas; na Irlanda existem pérolas de qualidade não tão excelente, que outrora foram perfeitas e caras, como as que estavam incrustadas na armadura de Júlio César; os pequenos búzios, importados do Egito e denominados "porcelletta", ${ }^{15}$ em Itália, são usados para a cosmética feminina.

A presente enumeração serve fundamentalmente para demonstrar que Amato pretende elucidar os leitores da sua obra com dados não exclusivamente técnicos, pondo ao seu dispor um manancial de conhecimentos que lhes será muito úteis para compreender a arte da medicina como uma forma integrada de cultura. Nesse sentido, o nosso humanista dedica-se ao trabalho aturado de compulsar fontes e de as explicar e atualizar à luz dos novos saberes. Não surpreende, pois, este método excursivo de apresentação da matéria médica, verdadeiramente desconcertante para algumas das atuais exigências sobre a elaboração técnica de um tratado desta natureza. Não deve, por isso, estranhar-se que o autor exiba aquela que é seguramente uma das suas marcas discursivas mais singulares, a capacidade de fazer derivar o assunto em apreço para matérias circunferentes. Já o havíamos identificado na tradução das enarrationes 39 e 52, deste mesmo segundo livro dos Comentários, respetivamente dedicadas ao vergalho e ao corno do veado. Em ambos os casos, resultou a inclusão dos tão importantes assuntos sobre o bezoar (lapis belzahart) e o unicórnio (unicornis). ${ }^{16}$

14 Deus da mitologia grega, filho de Posídon e Anfitrite.

15 Cf. Dizionario Universale Critico-Enciclopedico della Lingua Italiana Dell'Abbate d'Alberti di Villanuova, Tomo Quinto. Lucca, Presso Domenico Marescandoli, MDCCCIV: "PORCELLETTA, s. f. Porcellana vulgaris. Spezie d'Animale marino, che vive dentro um guscio simile a un pinocchio, di sostanza, e colore simile alla porcellana spezie di conchiglia. Le porcellette, e le blatte bizanzie si dissolvono, tenendole in infusione nel sugo di limoni. Ricett. Fior."; e Gabriel Fallopio, La Chirurgia. Venetia, Steffano Curti, 1675 (trad. ed. lat., 1571) , p. 285: "Ma io hò vn medicamento familiare fatto di succo de Limoni, $\&$ di Lumache, cioè di quele porcellete, che sono come Lumache marine, bianche, \& lucenti le quali si trouano appresso i muschiari, \& quelle Boteghe, oue si vendono cose odorate, $\&$ queste io pongo a molle, o infusione nel succo de Limoni fresco sin tanto, che detto succo consummi tutta quella porcelleta, \& resti come Fango molle, col qual poi vngo il luoco."

16 Cf. José Sílvio Moreira Fernandes; António Manuel Lopes AndRADE, "A Pedra Bezoar e o Unicórnio nos Comentários de Amato Lusitano a Dioscórides: propriedades, valor, tradição e tradução",Cadernos de Cultura Medicina na Beira Interior. Da pré-história ao século xx। 27 (2013), pp. 35-40. 
Voltando à presente análise, segue-se o comentário sobre as propriedades dos mexilhóes, do qual decorre uma conclusão necessariamente breve, sobre o uso medicinal deste molusco. Afirma Amato que, à semelhança das restantes conchas, a cinza obtida por incineração tem efeitos cáusticos. Até chegar a este ponto, o comentário deambulou pela manifestação da discordância quanto à identificação do mexilhão com a telina, ${ }^{17} \mathrm{em}$ Paulo Jóvio, com remissão para Ateneu, ${ }^{18}$ por uma breve revisão de literatura, para validar a opinião sobre a distinção entre mexilhão e telina, confirmada por Dioscórides, de acordo com a tradição hipocrática; por um excurso sobre pérolas; e, finalmente, sobre o ambiente natural onde evoluíram e vivem os mexilhôes.

Depara-se, neste passo, ao tradutor do texto amatiano com a maior dificuldade em determinar os critérios de diferenciação para os moluscos analisados. Podia parecer relativamente seguro optar por termos técnicos na tradução portuguesa, evitando-se a problemática decisão pela escolha de designações comuns, como mexilhão, para mitulus, conquilha, para tellina, e amêijoa, para chama. ${ }^{19}$ A tarefa não se afigura, porém, de fácil solução, uma vez que a tradição tratadística e taxonómica demonstra ter havido variadas aceçôes para designar cada um daqueles moluscos. A juntar aos autores citados ou apenas referidos por Amato Lusitano que escreveram sobre o assunto (Aristóteles, Hipócrates, Dioscórides, Plínio, Ateneu, Teodoro Gaza de Tessalonica e Paulo Jóvio), existe uma prolixa produção de comentários que tanto aditaram mais esclarecimento e apuramento tipológico, quanto incrementaram a dificuldade de resolução do problema colocado pelas diversas interpretações de autores clássicos, medievais e renascentistas. Refira-se, a propósito da complexa classificação das telinas, algumas das obras referidas por Rodrigo César Marques ${ }^{20}$ como as que mais contribuíram para a fascinante história destes bivalves: Belon (1554), Rondeletius (1555), Ulisse Aldrovandi (1606), Charleton (1674), Argenville (1742), Buonnani (1681), Lister (1696), Rumphius (1705), Languius (1722) e Adanson (1757). Dado que a história da classificação científica dos referidos bivalves não permite considerar como inteiramente seguras as denominaçôes adotadas pelos comentaristas,

17 Para uma análise da problemática classificação das tellinidae, cf. Rodrigo César MARQues, Anatomia e filogenia do género Eurytellina (Tellinidae: Tellinoidea). São Paulo, Instituto de Biociências, Universidade de São Paulo, 2012, Diss. Dout., Digital Library of Theses and Dissertations of the USP, pp. 1-12 e passim; e D. Koutsoubas; S. Galinou-Mitsoudi; S. Katsanevakis; P. Leontarakis; A. Metakatos \& A. ZENETOS, "II.5. Bivalve and gastropod molluscs of commercial interest for human consumption in the Hellenic seas", in C. Papakonstantinou, A. Zenetos, V. Vassilopoulou, \& G. Tserpes, eds., State of Hellenic fisheries. Athens, Hellenic Centre for Marine Research, Institute of Marine Biological Resources, 2007, pp. 70-84.

18 Refere-se a Ateneu de Náucrates (c. 150 d. C.) e à sua obra Deipnosophistai. Cf. ed. S. Douglas Olson, Athenaeus, The Learned Banqueters. Cambridge, Mass./London. Harvard University Press, Loeb Classical Library, 2007-2012.

19 Repete-se aqui a dificuldade de identificação sobre o bivalve que é referido. Nas edições de comentaristas ao tratado de Dioscórides, como as de Andrea Mattioli (1554) e Andrés Laguna (1555), as ilustrações apontam para uma distinção entre mituli, tellinae e chamae. Cf. infra, n. 36.

20 Cf. R. C. Marques, Anatomia..., op. cit., pp. 3-6. 
pelo menos desde a Antiguidade até ao Renascimento, optámos por usar, na presente tradução, respetivamente, as designaçóes mexilhóes, conquilhas e amêijoas, com a prudência de aceitar que cada um destes nomes encerra provavelmente uma maior variedade de bivalves. ${ }^{21}$ Ainda assim, no caso em que a comparação se faz entre os mexilhões e as telinas, parece mais prudente manter esta designação, em vez da denominação comum.

Retomando o comentário às conquilhas, diz Amato que são usadas na alimentação, por serem muito agradáveis ao paladar, embora a areia que muitas vezes trazem prejudique os rins, provocando nefrites. As amêijoas, pelo contrário, apresentam propriedades benéficas como estimulantes do ventre.

Quando delimitámos o presente núcleo de estudo no âmbito dos comentários de Amato a Dioscórides, tivemos a atenção dirigida a linhas de análise que, embora vinculadas a uma ordem sequencial, deveriam, todavia, concentrar uma determinada orientação, de onde pudesse ser retirado o sentido comentarista do autor. Concluímos, destarte, que existe um sentido expositivo, cuja sequência é composta sobretudo pela caracterização anatómica do animal em estudo; pelo ambiente natural onde vive e se desenvolve; pela denominação do género ou da espécie, com as respetivas polémicas, incluindo a discussão etimológica; pela tradição da tratadística; pelo confronto de fontes, com a arrolar de testemunhos, citações, títulos e comentaristas, referências históricas, mitológicas, astronómicas e bibliográficas; pela tradição popular; pela atividade comercial e pelos usos terapêuticos. Tais usos tanto podem dizer respeito à validação do que a tradição havia reportado, sobretudo a partir de autores canónicos na matéria (Aristóteles, Hipócrates, Plínio, Dioscórides e Galeno) ou, por outra parte, ao resultado de experiências realizadas por Amato Lusitano ou até de práticas que no seu tempo considerava admissíveis e verdadeiramente úteis e confortáveis para os doentes.

Por tudo isto e pela convicção que nos move de dar a conhecer o trabalho de uma das personalidades mais prestigiadas da história científica e cultural portuguesa, a tradução desta pequena seleção dos comentários de Amato Lusitano, que ora se apresenta pela primeira vez, com a natural reserva de que se trata de um trabalho sempre inacabado e imperfeito, representa uma tentativa de conciliação entre o conhecimento dos textos e os saberes que enformam a complexa heterogeneidade das culturas humanística e científica.

21 Cf. D. Koutsoubas et alii, "II.5. Bivalve and gastropod molluscs..., op. cit., pp. 70-84. 


\title{
IN DIOSCORIDIS ANAZARBEI LIBRVM SECVNDVM ENARRATIONES DOCTORIS AMATI LVSITANI MEDICI CELEBERRIMI.
}

\author{
De Echino marino

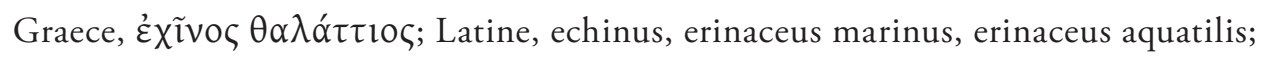

Hispanice, erizo dela mar, ourizo marino; Italice, ericcio marino; Gallice, ericio marino.

\section{Enarratio Primi Capitis}

Echinus tam aquatilis, quam terrestris, notissimum animal est, quod Latini erinaceum marinum et terrestrem appellant, quamquam Theodorus Gaza Thessalonicensis, in suo a se verso Aristotele, echinum marinum non aliter quam echinum interpretatus est, Plinium forte imitatus terrestrem vero echinum erinaceum vertit. Est igitur echinus marinus sive erinaceus marinus, piscis rotundus, aculeis armatus, veluti castanearum echinus, unde et nomen Ėxĩvov enim Graece, Latine hirtum vertunt non minus enim hirtus piscis iste est, quam castanearum calices, aculeis sive spinis armatus, quibus pedum vice ambulat rotaturve. Ceterum piscis iste esui idoneus est et mari Adriatico et Tyrrheno familiaris, quo pro lotio proritando multi vescuntur. Porro echinorum genera sunt plurima, quorum Aristoteles, quarto libro de Historia animalium, unum minutum spinis longis, praeduris, ornatum, non nisi in alto gurgite gigni solitum, maxime contra destillationes urinae laudat. Vnde Paulum Iovium hic decipi certum est, cum libello suo de Piscibus, capite 41, non hoc genus, sed aliud maius, echinometram, quasi echinorum matrem, aut matricem dicas, appellatam ab Aristotele, laudari contendat. Certum enim est, citato loco ab Aristotele non echinometram contra urinae destillationes laudari, sed potius minutum illud genus a nobis delineatum, ut legenti manifestum erit. At de utroque echino, Galenus, libro undecimo de Facultatibus simplicium medicamentorum, ita tradit: erinacei utriusque tum marini tum terrestris corpus ustum cinerem efficit, facultatis tum extergentis, tum digerentis tum detrahentis. Itaque eo quidam et ad excrescentia et ad sordida usi sunt ulcera. 


\title{
COMENTÁRIOS AO LIVRO II DE DIOSCÓRIDES DE ANAZARBO PELO CÉLEBRE DOUTOR AMATO LUSITANO
}

\author{
Sobre o ouriço-do-mar

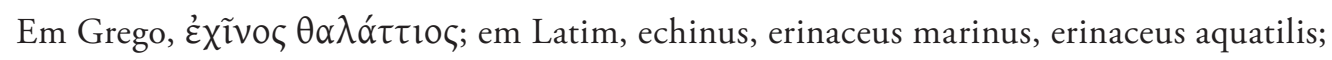 \\ em língua da Hispânia, erizo dela mar, ourizo marino; em língua da Itália, ericcio marino; em
} Francês, ericio marino.

\section{Comentário do primeiro capítulo}

O ouriço, tanto o da água como o da terra, é um animal muito conhecido, a que os latinos chamam ouriço-do-mar e ouriço terrestre, ${ }^{22}$ embora Teodoro Gaza de Tessalonica, na sua traduçáo de Aristóteles, tenha considerado ouriço-do-mar não de outro modo que ouriço, talvez imitando Plínio, que, na verdade, traduz terrestre por ouriço erináceo. Existe, portanto, o ouriço-do-mar ou erináceo marinho, peixe ${ }^{23}$ redondo, armado de espinhos, como um ouriço de castanheiro, pelo que se traduz em grego por દ̇xĩvov, em latim por "eriçado", pois tal peixe é, de facto, não menos espinhoso do que os invólucros das castanhas e armado de espinhos ou picos, com os quais, em vez dos pés, anda ou roda. Além disso, é um peixe comestível, comum nos mares Adriático e Tirreno, que muitos consomem como estimulante da urina. Existem, na verdade, muitos tipos de ouriços, entre os quais especificamente um, pequeno, que só costuma aparecer no fundo do mar, provido de longos espinhos, muito duros, que Aristóteles, no livro 4 da História dos Animais, recomenda muito contra defluxos urinários. Donde ser certo que nisto se engana Paulo Jóvio, quando, no capítulo 41 do seu opúsculo Sobre os Peixes, sustenta que não é de recomendar este género, mas a outro maior, designado por Aristóteles como o grande ouriço-do-mar, como se se dissesse mãe ou matriz de ouriços. ${ }^{24}$ É, efetivamente, verdade que, no citado passo de Aristóteles, não se nomeia o grande ouriço-do-mar contra defluxos urinários, mas antes o tipo mais pequeno por nós descrito, como ficará bem evidente a quem o ler. E, sobre um e outro destes ouriços, Galeno, no livro 11 do tratado Sobre as Propriedades dos Medicamentos Simples, assim diz: "o corpo queimado de ambos os ouriços, o do mar e o terrestre, feito inteiramente em cinzas, possui propriedades expurgativas, digestivas e evacuativas. E, conforme o que precede, foram usadas em excrescências e em chagas pútridas.

22 Ouriço-cacheiro.

23 Opção pela tradução de "piscis", com o seu sentido usual, para ser fiel ao entendimento epocal acerca da classificação tipológica deste tipo de animal marinho.

24 Para traduzir o jogo de palavras por semelhança fónica entre "echinometram" e "echinorum matrem", poder-se-ia também optar por combinações do género "madre e matriz" ou "mãe e madre", nas quais o segundo termo pareceria concitar sobretudo a aceção de órgão onde se gera e se desenvolve uma cria. 
De Erinaceo terrestri

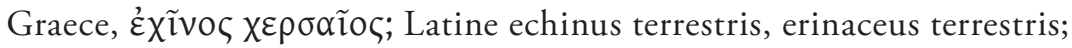

Hispanice, orico quacheiros; Italice, riccio terrestre;

Gallice, ericcio terrestre.

Enarratio capitis secundi

Echinus sive erinaceus terrestris, marino admodum similis est, qui taxo vel potius histrici similatur apparetve. Animal omni ex parte spinis horridum et aculeis armatum. Quod cum uvis aut fructibus aliis adhaeret, eos spinis transfixos, onustum incendit et ad cuniculos et nidi sui anfractus portat. Est enim animal hoc frigidum natura, multis scatens superfluitatibus. Qua de causa eius caro potius in medico usu, quam in continuo victu accipienda est. Habet enim animal hoc, ut obiter hoc notem, testiculos renibus adhaerentes, de quo Razes multa tractatu de Sexaginta animalibus scripta reliquit, quae omnia apocrypha et non Razis esse certissime crediderim. Ad multa tamen valet, quae Dioscorides in praesenti scribit, inter quae alopeciam pilorumve defluvium praecipue nominare est. 
Sobre o ouriço terrestre

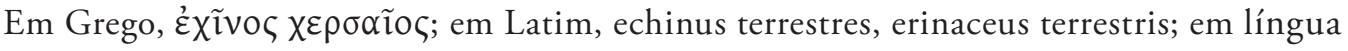
da Hispânia, orico quacheiros; em língua da Itália, riccio terrestre;

em Francês, ericcio terrestre.

Comentário do segundo capítulo

O ouriço ou erinácio terrestre é muito semelhante ao ouriço-do-mar, o qual se assemelha ou aparenta a um teixo ou, de preferência, a um histrix. ${ }^{25}$ É um animal inteiramente eriçado de picos e armado de espinhos. Pelo que, quando se fixa em uvas ou em outros frutos, trespassando-os com os picos, agita-se e, com o corpo carregado de alimentos, transporta-os para as tocas e para o seu ninho sinuoso. Trata-se, na verdade, de um animal frio e superabundante. Por essa razão, a sua carne deve ser mais apreciada para uso médico do que regularmente na alimentação continuada. Com efeito, tem este animal (para referir isto de passagem), os testículos ligados aos rins, e sobre ele Rasis deixou muitas coisas escritas no seu tratado Sobre os Sessenta Animais, que, creio, serem todas apócrifas e, seguramente, não de Rasis. É, todavia, eficaz em muitas situaçóes, que Dioscórides reporta no presente passo, entre as quais se deve sobretudo nomear a alopecia ou queda de cabelo.

25 Género de mamífero roedor. 


\section{De Hippocampo}

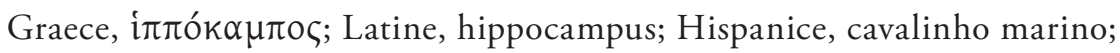

Italice, cavalin marino, cavalin ritorto, dragonetto; Galice, dragoneto

\section{Enarratio tertii capitis}

Nusquam quod equidem notaverim frequentius hippocampus, quam in Anconitano flexuoso hoc mari cernitur, ubi piscatores illum draconem, alii vero equulum circumflexum appellitant, pisciculus scilicet, subniger, equinum habens caput, oblongum et rotundum, collum vero latum multis clavatum ordinibus, nam cauda quadrata, subtilis ac circumflexa in eo cernitur. Verum hunc pisciculum marinum Dioscorides non descripsit, ipsius nomenclatura contentus,

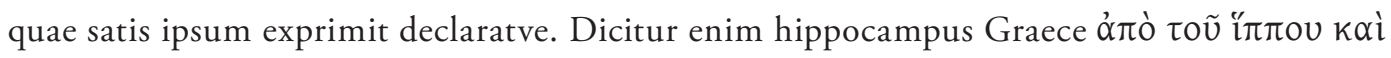
$\kappa \alpha ́ \mu \pi \tau \omega$, id est ab equo et flecto, quasi flexuosus equus. Vnde Mathiolus Senensis haec ignorans, plura non nisi absurda, de hippocampo scripsit. Inquit enim ille particulam hippo magnum significare, ut in hipposelino et hippomarathro sit. Ignorabat enim Mathiolus hippon equum crebrius significare, ut in praesenti evenit et capite 22, sequenti, ubi de hippopotamo, id est fluviatilis equi testiculo agit, ut sexentos alios praeteream locos, in quibus hippos pro equo accipitur. Ceterum, mulieres Anconitanae pisciculo isto in pulverem redacto et vino excepto, pro lacte evocando in potu utuntur, ac ea vero quoque, quae Dioscorides valere tradit, potente esse experimento compertum habeo. 
Sobre o cavalo-marinho

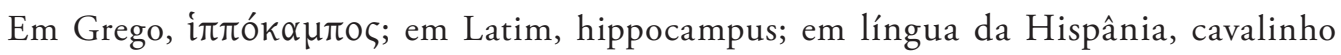
marino; em língua da Itália, cavalin marino, cavalin ritorto, dragonetto; em Francês, dragoneto

\section{Comentário do terceiro capítulo}

Em parte alguma, tenho observado mais frequentemente o cavalo-marinho do que aquele que se vê neste sinuoso mar de Ancona, onde os pescadores o costumam designar como dragão, outros ainda como cavalinho curvado, sem dúvida, um peixinho ${ }^{26}$ quase negro, que possui uma cabeça de cavalo, alongada e redonda, mas com um pescoço largo, guarnecido de muitos filamentos, nele se distinguindo ainda uma cauda esquadrada, fina e curvada. Na verdade, Dioscórides não descreveu este peixinho marinho, porque estava agradado com a designação atribuída, que traduz ou nomeia satisfatoriamente este animal. Diz-se "hipocampo", do grego

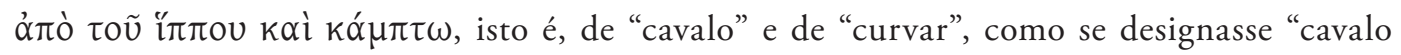
curvado”. É por esta razão que Matttioli de Siena, desconhecedor disto, escreveu muitas coisas que só podem ser absurdas sobre o cavalo-marinho. Afirma, de facto, que o radical hippo tem especial significado, como em hipposelinus" [salsa-de-cavalos] e em hippomarathrus [funcho bravo]. Ignorava, todavia, Mattioli que hippos significa mais frequentemente "cavalo" (como neste passo se verifica e, a seguir, no capítulo 22), ${ }^{27}$ quando ele faz referência aos testículos do hipopótamo, isto é, do "cavalo do rio", ${ }^{28}$ para não mencionar outras seiscentas referências, nas quais se aceita hippos por "cavalo”. De resto, as mulheres de Ancona usam tal peixinho, reduzido a pó e misturado com vinho, em bebida, como estimulante do leite materno, e este aspeto, que Dioscórides apresenta como válido, também eu comprovei que é eficaz através da experiência.

26 Opção semelhante à adotada para a tradução de "piscis". Cf. supra n. 23.

27 Amato refere-se à entrada, com a designação de enarratio 22, na qual irá tratar do assunto do hipopótamo.

28 Faz, neste passo, alusão ao comentário de Mattioli à obra de Dioscórides. 
De Purpuris et Bucinis

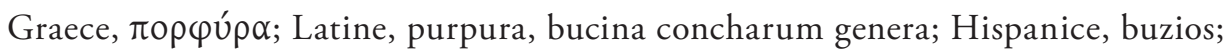
Italice, buccine

\section{Enarratio 4}

Purpura et bucinum e genere concharum in mari repertarum sunt. Nam purpura aculeis clavata, lingua digitali, firma, torosa et valida, ut reliqua conchylia perforare valeat, est. In cuius colli vena liquor ille pretiosissimus, purpureus dictus reperitur, quo purpureae Imperatorum et Regum vestes tingebatur. Hunc vero liquorem casu canem Herculis invenisse dictitant, quem Latini non solum liquorem vel sucum, et florem, verum etiam rorem et sarranum et tyrium, et saniem et pelagium, veluti Vitruvius, ostrum appellant. Extrahitur enim liquor iste a vivis purpuris, nam in mortuis illico evanescit. Qua de causa, piscatores vivas purpuras ad manus habere, maxime soliciti sunt. Vivunt autem purpurae extra mare, quinquagenis diebus saliva sua, si tamen aquam dulcem gustare illis contigerit, illico moriuntur. Latitant vero, ut placet Aristoteli, libro octavo de Historia animalium et libro quinto eiusdem voluminis, circa Canis ortum tricenis diebus. Plura vero apud Plinium legito et illius enarratorem Massarium libro nono, capite trigesimo sexto. Bucina vero, ut praediximus, purpurarum sunt species, minor tamen, quae ideo bucinum dicitur, quia ad similitudinem eius bucini quo sonus editur, est. Habet vero orificium quo sonus illiditur, ut ori sonantis applicetur, aptissimum. Hoc enim bucinum crederem ipse concham illam esse, qua olim Triton apud Olisiponenses canebat, ut eorum legato ad Tiberium Caesarem (referente Plinium) nuntiavit. Ceterum iis bucinis, ut diximus, purpurae sunt maiores, quae rostrum canaliculi modo oblongum, in quo lingua continetur habent, non nisi clavatum, ad turbinem usque, septenis fere in orbem aculeis, qui in bucino non reperiuntur. At commune purpuris et bucinis unum est, quod tot orbes sive volutas habent, quot annos. Bucina tamen non nisi petris adhaerent, circaque scopulos leguntur. Quarum pulvis, ut hodie operatur vel cinis, ut Dioscorides et Galenus suadent, ulcera maxime purgat. Bucinis hodie vice cadorum Lusitani nostri utuntur, praesertim ex India delatis, quae procul dubio, alba, nitida, margaritarum colore conspiciuntur et in maximo pretio habentur. Non est quoque in praesenti silere id quod dicit Dioscorides, scilicet, quod ex bucinis calx sit, cum hodie apud Indios, non alterius calcis quam huius, pro ferruminandis lapidibus et construendis parietibus copia detur. Sed cum de conchis agimos, non alienum erit, inter eas adnumerare eam in qua margaritae sive uniones nascuntur, cum de illis nec Dioscorides nec Galenus ullam fecerunt memoriam. Nascuntur igitur margaritae in concha non multum ab ostreorum conchis differente, ut cottidiana experientia testatur, et Plinius non siluit, libro Naturalis Historiae nono, capite trigesimo quinto, non quattuor aut ad summum quinque in 
Sobre as púrpuras e os búzios

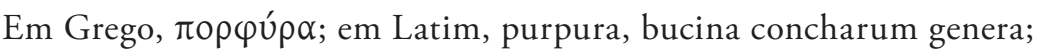
em língua da Hispânia, buzios; em língua da Itália, buccine

\section{Comentário quarto}

A púrpura e o búzio pertencem à espécie das conchas marinhas. A púrpura é guarnecida de pontas, com uma língua da grossura de um dedo, consistente, musculosa e forte, capaz de perfurar as restantes conchas. Na veia que tem no pescoço encontra-se o famoso líquido, de elevadíssimo valor, dito purpúreo, com o qual se tingiam as vestes purpúreas de imperadores e de reis. Na verdade, é comum dizer-se que o cão de Hércules encontrou por acaso este líquido, a que os Latinos chamam não só líquido ou seiva, e flor, mas também orvalho cartaginês e tírio, baba e, segundo Vitrúvio, púrpura do mar. Tal líquido é, na verdade, extraído de púrpuras vivas, pois quando morrem desaparece instantaneamente. Por essa razão, os pescadores sempre se esforçaram por apanhar as púrpuras com vida. Além disso, as púrpuras vivem cinquenta dias fora do mar, apenas com a sua saliva, mas, se lhes acontecer beber água doce, morrem imediatamente. Como refere Aristóteles, no livro 8 da sua História dos Animais e no livro 5 do mesmo volume, escondem-se, na verdade, durante trinta dias, próximo do nascimento da constelação do Cáo. Leia-se, pois, mais informação em Plínio e no seu comentador Massário ${ }^{29}$ (capítulo 30 do livro 9). Os búzios, na realidade, como afirmámos anteriormente, pertencem à espécie das púrpuras, mas são de menor tamanho. Diz-se precisamente "búzio" por se assemelhar à trombeta que emite som. Possui, de facto, um orifício, por onde se projeta o som e que se adapta perfeitamente à boca de quem toca. Com efeito, eu próprio acredito que este tipo de búzio é aquela concha, com a qual outrora Tritão cantava para os habitantes de Olisipo, como contou um seu embaixador, enviado a Tibério César (que Plínio refere). ${ }^{30}$ De resto, maiores do que estes búzios, como dissemos, são as púrpuras, que possuem uma boca meio alongada, apenas com um pequeno canal, onde se encontra a língua, só guarnecida de pontas até à parte cónica, geralmente dispostas em forma de um círculo com sete espinhos, inexistentes no búzio. Há, porém, um aspeto em comum nas púrpuras e nos búzios, o facto de terem tantos círculos ou volutas, quantos os anos. Os búzios, todavia, apenas aderem às pedras e são apanhados em redor de grandes calhaus. A sua cinza ou pó, conforme hoje se usa, de acordo com o que Dioscórides e Galeno aconselham, limpa com grande eficácia as chagas. Os Portugueses

29 Francisci Massarii Veneti in nonum Plinii de naturali historia librum castigationes et annotationes... Basileae, Froben, 1537.

$30 \mathrm{NH}, \mathrm{IX}, \mathrm{V}(4)$. 
concha una, ut ille tradit, inclusae, sed plures, centum numero excedentes, quae procul dubio, ut Arabes testantur, cordis et oculorum affectibus subveniunt. Nec audiendi sunt hodie nonnulli, qui ut aliquid novi afferre videantur, margaritarum contemnunt vires, ignorantes alioqui, margaritarum usum, rei medicae magnum ornamentum ac aegrotantibus non infimum nec contemnendum iuvamentum esse. Ex quibus conditum diamargariton dictum passim in officinis paratum habetur, sed quod margaritae integrae, vel perforatae in usu medico accipiendae sint, id recentiorum est commentum. Nam quae ex India afferuntur margaritae, Solis ingentissimo aestu, flavescunt, secus autem ex Peru provincia, ex qua hodie ad nos albissimae, rotundae admodum in magna quidem copia advehuntur. Quarum si quis exactam desiderat historiam, legat Plinium, loco citato, qui recte mea sententia uniones praestantissimos, in mari Rubro reperiri tradit, id quo nos hodie verum esse deprehendimus, cum Lusitani nostri, apud Ormusium, insulam Persiae, non procul a mari Rubro negotiantes, inde praestantissimos albissimosque portent uniones. Senio tamen confectae margaritae flavescunt et rugosae fiunt. In Hiberniae vero mari, hodie margaritae reperiuntur, non admodum tamen excellentes, olim tamen perfectissimas ac maximi pretii reperiri, Iulii Caesaris thorax indicat. Sunt quoque hodie bucina quaedam parva, quae ex Aegypto advehuntur, Italica voce porcelletta dicta, quibus mulieres pro decoranda facie maxime utuntur. Haec enim in suco limonis cum merguntur, liquefiunt et tanquam unguentum evadunt, quo mulieres ut dixi suas fucant genas et tanto magis, si parum sublimati, illi miscuerint. 
usam atualmente os búzios em vez de vasilhas, sobretudo os trazidos da Índia, que são indubitavelmente notáveis pela cor branca e brilhante das pérolas e têm um preço muito elevado. Náo é também de omitir, neste passo, o que diz Dioscórides, ou seja, a cal tem origem nos búzios, como a que, não diferente desta, hoje se usa com abundância, entre os Indianos, para colar pedras e construir paredes. Mas, em matéria de conchas, não será inoportuno enumerar entre elas a concha de onde nascem as pérolas ou pérolas únicas, ${ }^{31}$ já que nem Dioscórides nem Galeno dela minimamente fizeram qualquer registo. As pérolas nascem, portanto, numa concha, não muito diferente das conchas das ostras, como a experiência quotidiana comprova e Plínio não omitiu, no capítulo 35 do livro 9 da sua História Natural, não sendo, segundo diz, quatro ou cinco, no máximo, inclusas numa única concha, mas em maior número, ultrapassando cem, as quais, como atestam os Árabes, aliviam sem dúvida as afeções dos olhos e do coração. Atualmente não se deve dar ouvidos a alguns, que, parecendo trazer novidades, menosprezam as propriedades das pérolas, desconhecendo, além do mais, que o seu uso é um importante recurso da medicina e até um socorro, não desprezível nem despiciendo, para os doentes. Delas se obtém o composto denominado electuário de pérolas, preparado nas boticas de diversos lugares, mas, à luz da mais recente invenção, as pérolas inteiras ou abertas devem ser aceites nas práticas médicas. Com efeito, as pérolas que são trazidas da Índia apresentam uma cor amarelada, por causa do calor ardente do Sol, diferentes, porém, das do território do Peru, de onde hoje chegam em grande quantidade, alvíssimas e inteiramente redondas. Quem sobre elas quiser procurar a exatidão histórica tem de ler Plínio, no citado passo, onde, perfeitamente de acordo com a minha opinião, conta que as pérolas mais distintas se encontram no mar Vermelho, coisa que, nos nossos dias, compreendemos ser verdade, pelo facto de os Portugueses fazerem comércio perto do mar Vermelho, entre os habitantes da ilha persa de Ormuz, de onde trazem as tão distintas e alvíssimas pérolas únicas. Todavia, com o passar do tempo, as pérolas usadas adquirem uma cor amarelada e ficam com aspeto rugoso. Na verdade, no mar da Irlanda, encontram-se atualmente pérolas, mas não de grande qualidade; outrora, contudo, encontravam-se pérolas perfeitas e de enorme valor, como demonstra a armadura de Júlio César. Também existem atualmente alguns búzios pequenos, que chegam do Egito, que se denominam "porcelletta", ${ }^{32}$ no idioma itálico, e que as mulheres muito usam para embelezar o rosto. Na realidade, quando mergulhados em sumo de limão, liquefazem-se e tornam-se numa espécie de unguento, com o qual as mulheres, como disse, pintam as maçãs do rosto, e acrescentam-lhe mais se a cor deste tiver pouco realce.

31 Margarita é o nome grego para designar pérola. As margaritas são genericamente diferentes das pérolas que os Romanos chamavam uniones, visto que se tratava de uma única pérola produzida apenas por uma concha.

32 Cf. supran. 15. 


\section{De Mitulis}

Graece, $\mu u ́ \alpha \kappa \varepsilon \zeta$; Latine, myaces, mituli, musculi; Hispanice, Lusitanice, mixilhus; Italice, una sorte di lumache marini.

\section{Enarratio 5}

Non elevo iudicium Pauli Iovii viri doctissimi, cum dicat Athenaeum insequendo in eo libello quo de Romanis piscibus egit, mitulum tellinam esse, ut apud ipsum est videre capite quadragesimo primo, Dioscoridis forsan oblitus, qui mitulum a tellina differentem facit, ut ex praesenti capite et sequenti satis clare patente. Nec minus ex Hippocrate hoc satis probari potest, libro secundo de Diaeta, ubi mitulum a tellinis differentem facit, cum dicat: mituli vero et pectines ac tellinae, magis alvo secedunt. Est igitur mitulus conchae margaritiferae species quaedam, testa levi, subtili, nigricante, hirsutave, nam intus lucens, nitensve est, quae, ut tradit Plinius, libro nono capite trigesimo quinto, ubi de margaritis et unionibus agit, in Bosphoro Thracio, rufos ac parvos uniones producebat, at hodie mitulos non solum in mari, sed fluminibus intrantibus mare, non tamen margaritiferos observamus, quos musculos Latiniores appellant, quamquam non me lateat Theodorum Gazam, libro tertio de Historia animalium, mysticetum 
Em Grego, $\mu u ́ \alpha \kappa \varepsilon \zeta$; em Latim, myaces, mituli, musculi; em língua da Hispânia e em Português, mixilhus; em língua da Itália, una sorte di lumache marini.

\section{Comentário cinco}

Retiro a razão a Paulo Jóvio, homem extremamente douto, pelo facto de, seguindo Ateneu, afirmar, no livrinho que fez sair sobre os peixes de Roma, que o mexilhão é uma telina, ${ }^{34}$ como se pode verificar no capítulo 41 da sua obra, talvez esquecido de Dioscórides, que distingue o mexilhão da telina, como neste capítulo e nos seguintes ficará claramente exposto. Isto, ademais, pode ser satisfatoriamente verificado em Hipócrates, no livro 2 do tratado Sobre a Dieta, no qual também distingue o mexilhão da telina, afirmando "os mexilhôes, na realidade, diferem, sobretudo pela cavidade intestinal, das vieiras e das telinas”. O mexilhão é, portanto, uma espécie de concha (das que produzem pérolas), com uma casca leve, fina, escura e eriçada, brilhante ou luzidia no interior, a qual, segundo Plínio, no capítulo 35 do livro 9, onde trata do assunto das pérolas e das pérolas únicas, produzia, no Bósforo Trácio, pérolas avermelhadas e pequenas. Atualmente, observamos mexilhôes não só no mar, mas também nas embocaduras fluviais, mas não os que produzem pérolas, que os mais puristas designam por moluscos, apesar de Teodoro Gaza, no livro 3 do tratado Sobre a História dos Animais, traduzir "mysticetus" 35 ,

33 É de verificar que existe uma discrepância entre as ilustrações insertas nas edições dos comentaristas de Dioscórides, Andrés Laguna e Andrea Mattioli, e a interpretação que é por eles adotada. Cf. Andrés Laguna, Pedacio Dioscorides Anazarbeo, acerca de la materia medicinal y de los venenos mortiferos. Anvers, luan Latio, 1555, p. 126; e P. A. MATTIOLI, Commentarii in Libros..., op. cit., p. 160. Parece que este entendimento acerca dos "mexilhões" descritos e representados nas ilustrações pode também ser extensivo ao bivalve hoje cientificamente conhecido como arca noae. Cf. D. Koutsoubas et alii, "II.5. Bivalve and gastropod molluscs..., op. cit., pp. 74 e 75, figs. 4 e 5.

34 Na comparação específica entre o mexilhão e a telina, é mais conveniente usar na tradução o termo "telina" em vez de "conquilha", uma vez que parece haver aqui uma generalização extensiva a esta espécie, de modo a incluir possivelmente outros bivalves semelhantes ao mexilhão ou às conquilhas. Ver também a referência específica em Paulo Jóvio: De Romanis Piscibus libellus ad Ludovicum Borbonium Cardinalem, amplissimum, ed. Froben, 1531, cap. 41: "Sequuntur parvae illae Conchulae a veteribus latinis Mytili, a Romanis autem hodie Graeco nomine Tellinae nuncupatae...".

35 Termo preferível a "mystocetum", registado na edição de 1553. A tradição que reporta a designação usada por Aristóteles e traduzida por Teodoro Gaza, como neste passo é referido por Amato Lusitano, criou, além de registos diferenciados (mystocetus/mysticetus/mystakoketos), um imaginário que colocou em confronto a associação do nome a cetáceos, precisamente pelo facto de o animal em causa não possuir dentes, e a interpretação de Gaza que aponta para uma hipótese muito diferente, ao optar pela denominação musculus piscis (molusco). Esta questão tem acompanhado a história da tradução do texto aristotélico. Pouco mais de dois séculos depois da edição de Amato, podemos vê-la, por exemplo, na síntese que A. Camus escreveu no seu volume de notas sobre a referida obra de Aristóteles. Cf. A. Camus, Notes sur l'Histoire des Animaux d'Aristote. Paris, Chez la Veuve Desaint, 1783, pp. 540-541. 
in Aristotele, musculum vertisse, imo Hippocrates, citato loco, musculum diversum a mitulis facit. Verum mituli sua sponte in arenosis, extra mare, et fluviis mare intrantibus nascuntur, ut meminit Plinius citato libro, capite 51. Qui capite decimo libri tregesimi secundi, myacas in mitulos degenerare et in algosis non arenosis vivere affert. Ceterum, mituli, ut caetera conchilia, in victus usum veniunt, quorum cinis quoque causticum vim habet.

\section{De Tellinis}

Graece, $\tau \varepsilon \lambda \lambda \tilde{\mathrm{i}} v \alpha \varepsilon$; Latine, tellinae; Hispanice, brignigoís;

Italice, telline, calcinelli.

\section{Enarratio 6}

Haec conchulae quoque sunt et e conchyliorum genere, quae ubique in mari reperiuntur, et in victus usum cottidianum veniunt, gustui admodum gratae, verum ob arenulas quibus scatent, renibus officiunt et nephritim generant. 
em Aristóteles, por molusco e de até Hipócrates, no citado passo, diferenciar molusco de mexilhão. Na verdade, os mexilhóes nascem espontaneamente, fora do mar, em zonas arenosas e nas embocaduras dos rios, como recordou Plínio no já referido livro, ao capítulo 51. Conta-nos, ainda, no capítulo 10 do livro 32, que as conchas degeneraram em mexilhóes e vivem em locais com algas, não arenosos. Quanto ao resto, os mexilhões, à semelhança das restantes conchas, têm vindo a ser usados na alimentação e a sua cinza também possui propriedades cáusticas.

Sobre as conquilhas ${ }^{36}$

Em Grego $\tau \varepsilon \lambda \lambda \tilde{\imath} v \alpha \varepsilon$; em Latim, tellinae; em língua da Hispânia, brignigoís; em língua da Itália, telline, calcinelli.

\section{Comentário seis}

Ao género das conchas pertencem também estas de pequena dimensão, que se encontram em qualquer lugar no mar, e que têm vindo a ser usadas na alimentação quotidiana. São muito agradáveis ao paladar, mas, devido a virem cheias de grãos de areia, prejudicam os rins e provocam nefrites.

36 Para a problemática relativa à classificação deste bivalve, ver supra n. 17 e 19. Nas já referidas ilustrações das edições de Laguna e de Mattioli, parece claramente tratar-se da espécie de conquilha ou cadelinha existente em Portugal e no Mediterrâneo, a Donax trunculus (Linnaeus, 1758), correspondente à denominada $\tau \varepsilon \lambda \lambda \tilde{i} v \alpha /$ tellina. Cf. D. Koutsoubas et alii, "II.5. Bivalve and gastropod molluscs..., op. cit., p. 77, fig. 9.; Andrés Laguna, Pedacio Dioscorides..., op. cit., p. 126; e P. A. Mattiolı, Commentarii in libros..., op. cit., p. 160. 


\section{De Chamis}

Graece, $\chi \tilde{\eta} \mu \alpha 1 ;$ Latine, chamae.

\section{Enarratio 7}

Sunt ut paucis dicam chamae, conchyliorum genus, veluti plura alia, ut digiti, ungues, patellae et alia varia, quae Dioscorides praetermisit et eorum ius esculentum tantum alvum proritant. 
Sobre as amêijoas ${ }^{37}$

Em Grego, $\chi \tilde{\eta} \mu \alpha 1 ;$ em Latim, chamae.

\section{Comentário sete}

Farei apenas uma breve referência às amêijoas que são um género de conchas, como muitas outras que existem sob a forma de dedos, unhas, pratinhos e várias outras (que Dioscórides omitiu), cujo molho suculento muito estimula o ventre.

37 Trata-se, como já referimos, de outro caso de difícil opção terminológica, muito semelhante à que se nos deparou para a classificação dos mituli e das tellinae. O termo chamae, traduzido aqui necessariamente em sentido genérico, pode representar uma ampla variedade de bivalves, com formas semelhantes às das amêijoas. As mencionadas edições de Laguna e de Mattioli exibem também uma variedade deste tipo de bivalves que parece incluir espécies como berbigões ou até pequenas vieiras. Cf. D. Koutsoubas et alii, "Il.5. Bivalve and gastropod molluscs..., op. cit., pp. 76-78, figs. 8-13. 


\section{BIBLIOGRAFIA}

Bullens, Pieter; Gotthelf, Allan, “Theodore Gaza’s Translation of Aristotle’s De Animalibus: Content, Influence, and Date", Greek, Roman, and Byzantine Studies 47 (2007), pp. 469-513.

Camus, A., Notes sur l'Histoire des Animaux d'Aristote. Paris, Chez la Veuve Desaint, 1783.

Correia, Miguel; Palma, Jorge; Koldewey, Heather; Andrade, José P., "Can artificial holdfast units work as a habitat restoration tool for long-snouted seahorse (Hippocampus guttulatus Cuvier)?", Journal of Experimental Marine Biology and Ecology 448, 1 (2013), pp. 258-264.

Dizionario Universale Critico-Enciclopedico della Lingua Italiana Dell'Abbate d'Alberti di Villanuova, Tomo Quinto. Lucca, Presso Domenico Marescandoli, MDCCCIV.

Fernandes, José Sílvio Moreira; Andrade, António Manuel Lopes, "A Pedra Bezoar e o Unicórnio nos Comentários de Amato Lusitano a Dioscórides: propriedades, valor, tradição e traduçáo", Cadernos de Cultura Medicina na Beira Interior. Da pré-história ao século XXI 27 (2013), pp. 35-40.

Fallopio, Gabriel, La Chirurgia. Venetia, Steffano Curti, 1675 (trad. ed. lat., 1571).

Geana koplos, Deno John, “Theodore Gaza, a Byzantine Scholar of the Palaeologan 'Renaissance' in the Early Italian Renaissance (c. 1400-1475)", Constantinople and the West, Essays on the Late Byzantine (Palaeologan) and Italian Renaissances and the Byzantine and Roman Churches. Madison WI, 1989, pp. 68-90.

Jóvio, Paulo, De Romanis Piscibus libellus ad Ludovicum Borbonium Cardinalem, amplissimum, ed. Froben, 1531.

Laguna, Andrés, Pedacio Dioscorides Anazarbeo, acerca de la materia medicinal y de los venenos mortiferos. Anvers, Iuan Latio, 1555.

Koutsoubas, D.; Galinou-Mitsoudi, S.; Katsanevakis, S.; Leontarakis, P.; Metaxatos, A. \& ZeNETOS, A., "II.5. Bivalve and gastropod molluscs of commercial interest for human consumption in the Hellenic seas", in C. Papakonstantinou, A. Zenetos, V. Vassilopoulou, \& G. Tserpes, eds. State of Hellenic fisheries. Athens, Hellenic Centre for Marine Research, Institute of Marine Biological Resources, 2007, pp. 70-84.

Marques, Rodrigo César, Anatomia e filogenia do género Eurytellina (Tellinidae: Tellinoidea), Diss. Dout. São Paulo, Instituto de Biociências, Universidade de São Paulo, Digital Library of Theses and Dissertations of the USP, 2012.

Mattioli, Pietro Andrea, Commentarii in libros sex Pedacii Dioscoridis Anazarbei, de medica materia. Venetiis, apud Vincentium Valgrisium, 1554.

Mattioli, Pietro Andrea, Apologia adversus Amathum Lusitanum, cum censura in eiusdem enarrationes. Venetiis, Vincentii Valgrisii \& Balthassar Costantini, 1558.

Massário, Francisco, In nonum Plinii de naturali historia librum castigationes et annotationes... Basileae, Froben, 1537.

Olson, S. Douglas, Athenaeus, The Learned Banqueters. Cambridge, Mass./London, Harvard University Press, Loeb Classical Library, 2007-2012.

Silva, Maria de Fátima de Sousa e, Aristóteles, História dos animais, vol. I, 2006; vol. II. Lisboa, INCM, 2008. 
A partir dos alvores do século XVI, a matéria médica torna-se indiscutivelmente um tema de primeira grandeza entre os membros da República das Letras, objecto de estudo e de controvérsia entre os mais notáveis humanistas europeus, em particular entre os cultores da arte médica. Entre os autores em destaque neste volume encontram-se, à cabeça, os nomes de Amato Lusitano, Garcia de Orta e Nicolás Monardes, famosos pelos contributos valiosos que deram para o conhecimento do mundo natural. 0 volume encontra-se dividido em duas partes: a primeira, subordinada ao título "Humanismo e Ciência", alberga os estudos que versam sobre todos os autores estudados, à excepção de Amato Lusitano; a segunda está reservada a um conjunto de trabalhos dedicados exclusivamente ao médico albicastrense, cuja autoria se fica a dever, em boa parte, aos membros da equipa do projecto de I\&D "Dioscórides e o Humanismo Português: os Comentários de Amato Lusitano", tomando, por isso, 0 seu próprio título. Nesta segunda parte, oferece-se, desde já, aos leitores uma amostra significativa do trabalho desenvolvido no âmbito do projecto e que culminará, assim se espera, na edição e tradução integral para língua portuguesa das quatro obras previstas de Dioscórides, Amato Lusitano e Pietro Andrea Mattioli. 
